\title{
Rectal Serrated Adenocarcinoma
}

National Cancer Institute

\section{Source}

National Cancer Institute. Rectal Serrated Adenocarcinoma. NCI Thesaurus. Code C96487.

A rare, invasive rectal adenocarcinoma characterized by the presence of a malignant infiltrate with serrated glandular architecture. 